\title{
Assessment of modernized GPS L5 SNR for ground-based multipath reflectometry applications
}

\author{
Sajad Tabibi $^{\text {a,* }}$, Felipe G. Nievinski ${ }^{\text {b }}$, Tonie van Dam ${ }^{\mathrm{a}}$, João F.G. Monico ${ }^{\mathrm{b}}$ \\ ${ }^{a}$ University of Luxembourg, Faculty of Science, Technology, and Communication, Research Unit of Engineering Sciences (RUES), Luxembourg \\ ${ }^{\mathrm{b}}$ São Paulo State University, Faculty of Sciences and Technology, Department of Cartography, Spatial Geodesy Study Group (GEGE), Brazil
}

Received 2 June 2014; received in revised form 17 November 2014; accepted 20 November 2014

Available online 26 November 2014

\begin{abstract}
Global Positioning System (GPS) signal-to-noise ratio (SNR) measurements can be employed to retrieve environmental variables in multipath reception conditions, whereby direct or line-of-sight transmission is received simultaneously with coherent reflections thereof. Previous GPS SNR multipath studies of soil moisture and snow depth have focused on the legacy GPS L1 and L2 bands. In the present paper, short-delay, near-grazing incidence multipath from the L5-band GPS SNR is assessed for its value in detecting soil moisture and snow depth. The L5 signal will become more important in the future because of compatibility and interoperability among the different global satellite navigation systems. The L5 results are compared with L2C estimates to determine whether the L2C-L5 differences (given their differing power budgets and their modulation properties) are significant. To address these questions, measurements and simulations were employed. A physically-based multipath simulator was enhanced to investigate the differences between parameter retrievals for the L2C and the L5 GPS signals. Parameter retrievals from synthetic observations for different scenarios were compared. Comparisons included varying reflector height, surface material, and surface roughness. Measurements from two GPS stations in Colorado, USA, were used to retrieve soil moisture and snow depth conditions. Over a 153-day period that encompassed the catastrophic 2013 Colorado flooding event, L2-derived volumetric soil moisture had an RMS difference of $0.042 \mathrm{~cm}^{3} / \mathrm{cm}^{3}$ while the L5 RMS difference was $0.034 \mathrm{~cm} /$ $\mathrm{cm}^{3}$ with respect to in-situ data (values of volumetric soil moisture range between 0.04 and $0.34 \mathrm{~cm}^{3} / \mathrm{cm}^{3}$ ). In a separate $483-\mathrm{day} \mathrm{cam}^{-}$ paign, L5-derived snow depth estimates were compared to L2C-derived values and found strongly correlated, deviating from a one-toone relationship by only $0.00001 \pm 0.0064 \mathrm{~cm} / \mathrm{cm}$. These results indicate the absence of any detectable biases in L5 as compared to L2C for retrieving soil moisture and snow depth from GPS SNR multipath observations.
\end{abstract}

(C) 2014 COSPAR. Published by Elsevier Ltd. All rights reserved.

Keywords: GPS; Multipath; Reflectometry; Coherent; Modernization

\section{Introduction}

The Global Positioning System (GPS) was originally designed for positioning, navigation, and timing (PNT). However, several authors have demonstrated that GPS reflections in a bi-static configuration of L-band microwave radar (GPS Reflectometry, GPS-R - see Gleason et al. (2009), Jin et al. (2014), and references therein) can also

\footnotetext{
* Corresponding author.

E-mail address: sajad.tabibi@gmail.com (S. Tabibi).
}

be used for remote sensing purposes. There is a type of GPS-R that relies on the multipath reception of simultaneously and coherently recorded directly and reflected signals. It employs signal-to-noise ratio (SNR) measurements for retrieving environmental parameters such as soil moisture (Kavak et al., 1998; Larson et al., 2008; RodriguezAlvarez et al., 2011; Chew et al., 2014; Alonso-Arroyo et al., 2014), snow depth (Jacobson, 2008; Larson et al., 2009; Rodriguez-Alvarez et al., 2012; Nievinski and Larson, 2014d; Jin and Najibi, 2014), vegetation growth (Small et al., 2010; Rodriguez-Alvarez et al., 2011; Wan 
et al., 2014), and sea level variations (Anderson, 2000; Larson et al., 2013; Löfgren et al., 2014). The technique samples the environment over a sizable area, e.g., $\sim 1000 \mathrm{~m}^{2}$ in the vicinity of a $2-\mathrm{m}$ tall GPS antenna. It is known under various names: GPS Interference Pattern Technique (Rodriguez-Alvarez et al., 2011), GPS Interferometric Reflectometry (Larson et al., 2010) - which also refers to the unrelated replica-free reflectometry of Rius et al. (2012), SNR-based GPS multipath reflectometry (Nievinski and Larson, 2014b), or simply SNR-based GPS reflectometry (Löfgren et al., 2014). It is also possible to do multipath reflectometry with observables other than SNR, such as carrier-phase (Ozeki and Heki, 2012; Najibi and Jin, 2013) and pseudorange (Larson and Small, 2014).

Some researchers have used a custom designed GPS antenna coupled with a commercial off-the-shelf (COTS) receiver to record multipath signals (Rodriguez-Alvarez et al., 2011); others have employed a completely COTS antenna/receiver system in a setup dedicated for environmental monitoring, normally deployed tipped towards the horizon, sometimes upside-down (Kavak et al., 1998; Anderson, 2000; Jacobson, 2008; Löfgren et al., 2014). In contrast, Larson et al. (2008) first demonstrated that SNR measurements from COTS equipment and upright setups in existing GPS sites - deployed for positioning purposes - are in a good agreement with nearby precipitation records and land surface model predictions for soil moisture fluctuations. In a more recent paper, Larson et al. (2010) compared L2C SNR estimates of soil moisture with data from a network of volumetric soil moisture sensors, at a site in Marshall, Colorado. The authors found excellent agreement between the GPS and sensor estimates of soil moisture (correlations between 0.9 and 0.76 ) for non-snow and non-freezing conditions over a three-month period. Again using the L2C signal, Larson et al. (2009) tracked the snow depth from two separate snow-storms in Marshall, Colorado; agreement with three nearby ultrasonic snow depth sensors was very good throughout the history of the storms.

In parallel to efforts in GPS multipath reflectometry (GPS-MR), the GPS modernization program seeks (i) to offer enhanced positioning accuracy and reliability as well as improved measurement precision; (ii) to address robustness and sensitivity by improving frequency diversity; (iii) to increase signal power and modify signal structure in order to build additional capability for integrity (Misra and Enge, 2011). Both civil modernized signals, L2C and L5, offer high cross-correlation performance, improving weak-signal acquisition. The L5 signal will become more important in the future because of compatibility and interoperability among the different satellite navigation systems.

Previous GPS SNR multipath studies of soil moisture and snow depth focused on the legacy GPS L1 and L2 bands. In the present paper, short-delay near-grazing incidence multipath observed in SNR from the newest GPS signal in the L5 band has been assessed for the first time for GPS-MR purposes. In Section 2 the background con- cepts of GPS-MR and the modernized GPS civil signals are reviewed. Then a physically-based forward model is used to simulate the effect of different variables on the predicted SNR observations. These variables include reflector height, random surface roughness, and surface material. The model developed by Nievinski and Larson (2014b) is modified for this purpose. The error in the parameter retrievals was estimated by comparing them to the known input parameters. Finally, the GPS-derived snow depth and soil moisture derived from L2C and L5 at two sites in Colorado, USA are experimentally analyzed.

\section{Background}

A GPS antenna simultaneously tracks all satellites in view. A typical antenna gain pattern is omni-directional in azimuth and quasi-hemispheric in elevation angle. The antenna receives energy directly from the satellite transmitter and also from the ground-reflected signals. This multipath reception condition is one of the main error sources in high-precision GPS studies (Elósegui et al., 1995; King and Watson, 2010).

Geodetic-quality GPS antennas are designed to boost the energy from the direct signal that is predominantly right-handed circularly polarized (RHCP). Geodetic antennas also suppress left-handed signals (LHCP) as much as possible (Fig. 1). Upon reflection, the RHCP wave generates two orthogonally polarized waves (LHCP and RHCP). The polarization of the reflected waves depends on the permittivity of the surface and the angle of incidence. Thus, it is possible to receive both direct and reflected signals simultaneously.

Legacy GPS signals include an open coarse/acquisition (C/A) signal on the L1 band as well as protected/encrypted signals $(\mathrm{P}(\mathrm{Y}))$ on both $\mathrm{L} 1$ and $\mathrm{L} 2$ bands. A second signal, L2C, was open to civilians and was implemented in September 2005 with the successful launch of the first block IIR-M satellite (Table 1). Subsequently, an L5 signal started broadcasting in a protected aeronautical radio navigation service band, that was intended to support safety-of-life applications; the L5 signal has been implemented with the launch of the first block IIF in May 2010 (GPSD-USAF, 2012).

\subsection{SNR-based GPS Multipath Reflectometry}

The key to GPS-MR is the interference pattern between the direct and reflected signals under multipath conditions. Although all GPS measurements are affected by multipath, SNR measurements are primarily used in this type of GPSMR. SNR indicates the ratio of the signal power to the noise power (integrated over a given bandwidth) and has conventionally been used for comparing tracking channels. SNR is straightforward to analyze for the multipath signature as there is no need to account for ranging effects, such as ephemerides, atmospheric delays, clock errors, etc., parameters that normally need to be known precisely for 


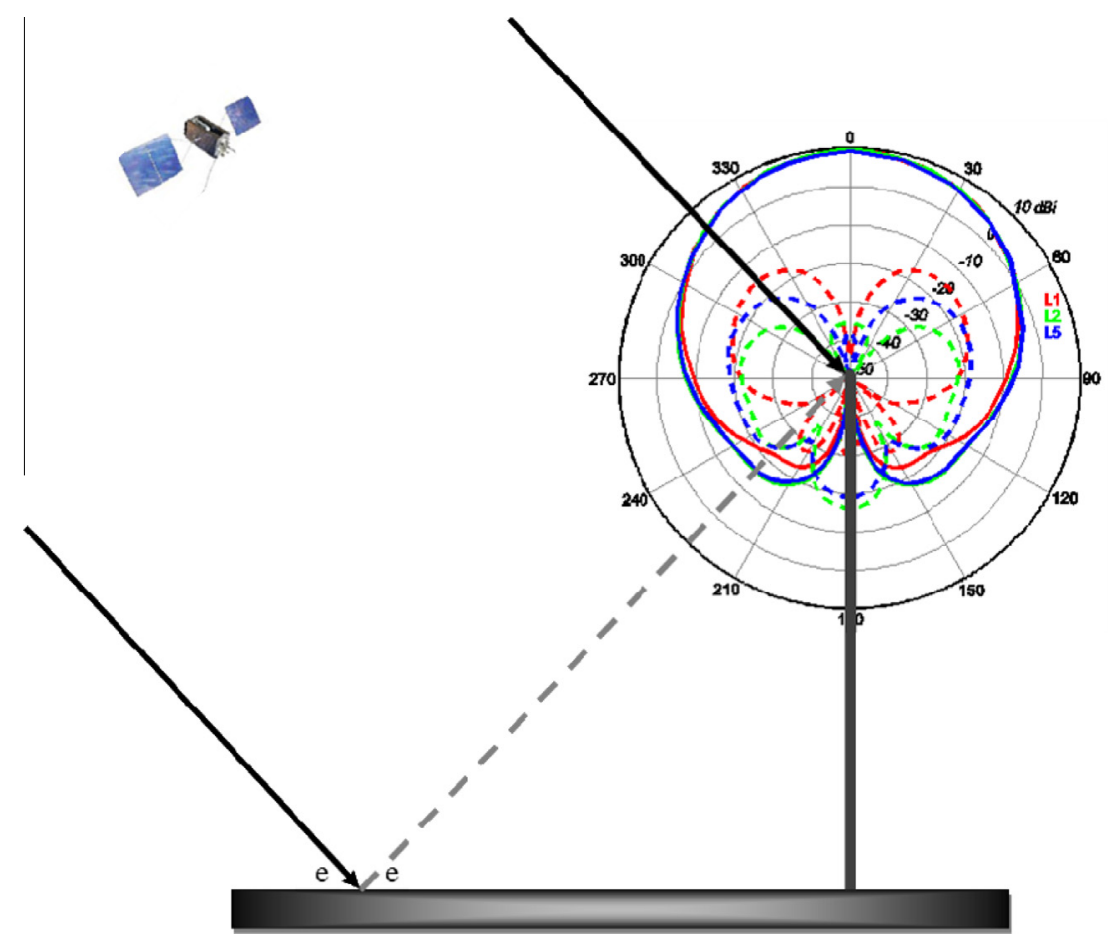

Fig. 1. Gain patterns for RHCP (solid lines) and LHCP signals (dashed lines) for the antenna model LEIAR20 and at three carrier frequencies. The direct signal is shown in black solid arrows, enter the gain pattern at a direction to the satellite elevation angle (e). For horizontal ground surfaces, reflected signal (grey dashed arrow) pierces the gain pattern at the negative elevation angle.

carrier-phase and pseudorange measurements (Larson et al., 2009).

The SNR oscillations depend on the reflectivity of the surface, which can be related to the permittivity of the surface. At GPS carrier frequencies, the soil permittivity is a function of its water content (Hallikainen et al., 1985; Dobson et al., 1985). Furthermore, at near-grazing specular incidence in contrast to radar backscattering radars, the top few centimeters $(\sim 5 \mathrm{~cm})$ of the soil dominate the reflectivity (Chew et al., 2014). Thus, SNR oscillations can provide information on near-surface changes in soil moisture.

The SNR at any instant is a function of the direct signal power, the reflected power, and the phase difference between the two. As a satellite crosses the sky, the reflection geometry changes, resulting in a pattern of constructive and destructive oscillations in the recorded power. These oscillations in turn affect the SNR. The modulation frequency of the oscillations depends on the vertical distance between the antenna and the reflecting surface and the elevation angle of the satellite.

As GPS satellites rise and set once or twice daily, their reflection points can be mapped around the antenna. The GPS footprint for a ground-based antenna can be approximated as the first Fresnel zone, an ellipse dependent on the height of the antenna and the satellite elevation angle (Larson and Nievinski, 2013). As the L5 carrier wavelength is 1-cm larger than that of the L2C signal, the first Fresnel zone is $\sim 6 \%$ larger than that for L2 for an elevation angle of $5^{\circ}$. Moreover, the wavelength can affect the depth to which soil moisture is sensed (Chew et al., 2014). SNR observations of L1 and L2 signals transmitted from older block IIR satellites as recorded by a Trimble NetRS receiver demonstrate that, for this satellite/receiver configuration, the legacy L2 $\mathrm{P}(\mathrm{Y})$ signal has greater power losses, compared to L1 (Larson et al., 2010). Larson et al. (2010) also compared L1 to the modernized L2C signals from the block IIR-M satellites; L2C was found to be less distorted than that of L1-C/A, a result which Nievinski and Larson (2014b) later attributed to the longer code of L2C.

\subsection{GPS modernization}

One of the primary goals of the GPS modernization program was to launch new satellites with additional navigation signals for both civil and military users such that the precision and satellite signal availability improves. The new civil signals improve the tracking sensitivity and measurement accuracy that help us overcome the inherent weaknesses of the C/A signal and (semi-) codeless tracking of the encrypted $\mathrm{P}(\mathrm{Y})$ code.

The modernization program has introduced two new military and two new civil signals (GPSD-USAF, 2012). The new civil GPS signals are centered at 1227.60 and 1176.45 MHz and are denoted L2C and L5. L2C is limited to a single bi-phase shift key (BPSK) component, unlike the new L5 signal which consists of two BPSK components in phase quadrature. Table 1 summarizes all properties of legacy and modernized GPS signals that are relevant for the analysis. 
Table 1

GPS signal modulations.

\begin{tabular}{|c|c|c|c|c|c|c|c|c|c|}
\hline \multirow[t]{2}{*}{ Block } & \multirow{2}{*}{$\begin{array}{l}\text { Carrier }(\mathrm{cm}) \\
(\mathrm{MHz})(\times 10.23 \mathrm{MHz})\end{array}$} & \multirow[t]{2}{*}{ Code Abbr. } & \multirow[t]{2}{*}{ Chipping rate (Mchip/s) } & \multicolumn{3}{|l|}{ Code length } & \multicolumn{3}{|c|}{ Effective chip width } \\
\hline & & & & (chip) & $(\mathrm{ms})$ & $(\mathrm{km})$ & (chip) & (ns) & $(\mathrm{m})$ \\
\hline All & $\begin{array}{l}\text { L1 } \\
19.0 \\
1,575.420 \\
154\end{array}$ & $\begin{array}{l}\mathrm{C} / \mathrm{A} \\
\mathrm{P}(\mathrm{Y})\end{array}$ & $\begin{array}{l}1.023 \\
10.23\end{array}$ & $\begin{array}{l}1,023 \\
6.187 \times 10^{12}\end{array}$ & $\frac{1}{6.048 \times 10^{8}}$ & $\begin{array}{l}299.792 \\
1.813 \times 10^{11}\end{array}$ & $\begin{array}{l}1 \\
1\end{array}$ & $\begin{array}{l}977.517 \\
97.752\end{array}$ & $\begin{array}{l}293.052 \\
29.305\end{array}$ \\
\hline IIR-M, IIF & L2 & $\mathrm{CM}$ & 0.5115 & 10,230 & 20 & $5,995.849$ & $1 / 2$ & 977.517 & 293.052 \\
\hline IIR-M, IIF & 24.4 & $\mathrm{CL}$ & 0.5115 & 767,250 & 1,500 & $449,688.687$ & $1 / 2$ & 977.517 & 293.052 \\
\hline All & $\begin{array}{l}1,227.600 \\
120\end{array}$ & $\mathrm{P}(\mathrm{Y})$ & 10.23 & $6.187 \times 10^{12}$ & $6.048 \times 10^{8}$ & $1.813 \times 10^{11}$ & 1 & 97.752 & 29.305 \\
\hline IIF & $\begin{array}{l}\text { L5 } \\
25.5 \\
1,176.450 \\
115\end{array}$ & $\begin{array}{l}\text { I5 } \\
\text { Q5 }\end{array}$ & $\begin{array}{l}10.23 \\
10.23\end{array}$ & $\begin{array}{l}10,230 \\
10,230\end{array}$ & $\begin{array}{l}1 \\
1\end{array}$ & $\begin{array}{l}299.792 \\
299.792\end{array}$ & $\begin{array}{l}1 \\
1\end{array}$ & $\begin{array}{l}97.752 \\
97.752\end{array}$ & $\begin{array}{l}29.305 \\
29.305\end{array}$ \\
\hline
\end{tabular}

The L2C signal is further decomposed into two channels: a data channel $(\mathrm{CM})$ and a data-less channel (CL) that does not possess a navigation message. $\mathrm{CM}$ and $\mathrm{CL}$ are modulated by a medium-length code and a long code, respectively (Fontana et al., 2001). The chipping rate is limited for $\mathrm{L} 2 \mathrm{C}$ to ensure its spectral separation from the new military signals broadcast in the same carrier frequency band. Furthermore, L2C also had to avoid conflict with the legacy military signal, $\mathrm{P}(\mathrm{Y})$, something that is guaranteed through phase quadrature. Yet it was still desirable to have two channels, therefore $\mathrm{CM}$ and $\mathrm{CL}$ are combined in a chip-by-chip time multiplexer.

Chipping rate is the most important parameter of the code modulation to be considered in a multipath investigation. For L5, the chipping rate is ten times higher than that for either C/A or L2C (Spilker and Van Dierendonck, 2001). A higher chipping rate results in better rejection performance for large interferometric delays but the higher chipping rate is ineffective in suppressing delays that are much smaller than the code chip width (Table 1). This interplay between interferometric delay and code chipping rate will impact the amount of interferometric power resulting from the receiver correlation of a clean replica against the recorded multipath (direct plus reflected) signal. Code length also impacts SNR through the amount of cross-channel self-interference. The C/A code is the most susceptible to this problem as it is the shortest.

Like the L2C signal, the new L5 also has two codes (I5 and Q5) that include a data-free channel (Q5). No military signal is planned for L5, thus there is no requirement for time multiplexing of the codes, and their separation is achieved through phase quadrature. These dataless signals (L2C-CL and L5-Q5) improve the receiver's signal acquisition and tracking performance, both of which are very helpful when operating in low-SNR environments as these dataless signals enable the use of a phase-locked loop instead of a Costas loop, improving tracking sensitivity by $\sim 6 \mathrm{~dB}$ (Table 2 ).

The new L2C and L5 signals are very close in wavelength (24.4 and $25.5 \mathrm{~cm}$ receptively) and share other modernized features. Thus, these signals would be expected to offer similar performance for GPS-MR. However, L5 has a faster chipping rate, making the main peak in the auto-correlation function sharper by a factor of ten (GPSD-USAF, 2012). Furthermore, L5 has a minimum specified received power greater than L1 C/A and L2C (Table 2); therefore the L5 signal would be expected to offer better tracking noise performance.

\section{SNR multipath model}

In this section we use the forward model of Nievinski and Larson (2014b), that has been extended from that of Zavorotny et al. (2010), to obtain GPS multipath as observed by a particular antenna. The goal is to compare the theoretical performance of L5 versus L2 and L1 in deriving estimates of soil moisture and snow depth under different conditions. For extensive details on the theoretical formulation, the reader is referred to Nievinski and Larson (2014b).

The observed SNR $=\mathrm{tSNR}+\mathrm{dSNR}$ (in units of watts per watt) can be modeled as the sum of a trend (tSNR) and detrended interference fringes (dSNR) (Nievinski and Larson, 2014b):

$\mathrm{tSNR}=\left(P_{d}+P_{r}\right) P_{n}^{-1}=P_{d}\left(1+P_{i}\right) P_{n}^{-1}$

$\mathrm{dSNR}=\mathrm{aSNR} \cos \phi_{i}$

aSNR $=2 \sqrt{P_{d}} \sqrt{P_{r}} P_{n}^{-1}=2 P_{d} \sqrt{P_{i}} P_{n}^{-1}$

where aSNR can be interpreted as the amplitude of the detrended SNR oscillations (assumed perfectly sinusoidal); more rigorously, aSNR represents the envelope of dSNR (for the general case in which the trigonometric factor $\cos \phi_{i}$ is non-sinusoidal).

The powers $P_{d}, P_{r}$, and $P_{n}$ refer to the direct signal, the reflected signal, and noise. The quantities $P_{i}=P_{r} / P_{d}$ and $\phi_{i}=\phi_{r}-\phi_{d}$ are the interferometric power and interferometric phase, respectively. It should be noted that trend (tSNR) and fringes (dSNR) are not the separate effects of each direct and reflected signals, respectively. 
Table 2

Comparison of civil signal powers; values in parentheses are received power levels relative to $\mathrm{L} 1 \mathrm{C} / \mathrm{A}$.

\begin{tabular}{|c|c|c|c|c|c|}
\hline Carrier & Signal & Total received power $(\mathrm{dBW})$ & Multiplexing (dB) & Tracking loop method (dB) & Effective power (dB) \\
\hline L1 & $\mathrm{C} / \mathrm{A}$ & $-158.5(0)$ & $0.0(0)$ & $0.0(0)$ & $-158.5(0)$ \\
\hline \multirow[t]{2}{*}{$\mathrm{L} 2$} & $\mathrm{CM}$ & $-160.0(-1.5)$ & $-3.0(-4.5)$ & $0.0(-4.5)$ & $-163.0(-4.5)$ \\
\hline & $\mathrm{CL}$ & & $-3.0(-4.5)$ & $+6.0(+1.5)$ & $-157.0(+1.5)$ \\
\hline \multirow[t]{2}{*}{ L5 } & I5 & $-154.9(+3.6)$ & $-3.0(+0.6)$ & $0.0(+0.6)$ & $-157.9(+0.6)$ \\
\hline & Q5 & & $-3.0(+0.6)$ & $+6.0(+6.6)$ & $-151.9(+6.6)$ \\
\hline
\end{tabular}

Partial antenna power gains for right- and left-handed circularly polarization (RHCP and LHCP, respectively), evaluated in the direct and reflected directions, are denoted as $G_{d, r}^{R, L}$, while $\Phi_{d, r}^{R, L}$ are the respective antenna phase components. Their combined effect is represented by polarization- and direction-dependent antenna complex length components (in meters), e.g.,

$L_{d}^{R}=L_{\text {iso }} \sqrt{G_{d}^{R}} \exp \left(\iota \Phi_{d}^{R}\right)$

for the direct RHCP signal, where $L_{\text {iso }}$ corresponds to an isotropic antenna and with $1=\sqrt{-1}$ denoting the imaginary unit.

Taking $P_{d}^{R}$ as the direction-dependent RHCP power component available for direct reception by an isotropic antenna $\left(P_{d}^{L}\right.$ can be neglected in GPS), the direct and interferometric powers can be expressed as:

$P_{d}=W_{d} P_{d}^{R} G_{d}^{R}$

$P_{i}=W_{i} X^{2} S^{2} / G_{d}^{R}$

where the direct and interferometric Woodward function, $W$, can both be approximated as unity, given the small interferometric delays involved in short-antenna installations (Nievinski and Larson, 2014b). The $X^{2}$ power factor stems from $X=X^{R}+X^{L}$, the complex-valued surface/ antenna coupled coefficient. In its turn, $X$ is expressed in terms of its RHCP- and LHCP-producing components,

$X^{R}=L_{\text {iso }}^{-1} L_{r}^{R} R^{S}$

$X^{L}=L_{\mathrm{iso}}^{-1} L_{r}^{L} R^{X}$

respectively, functions of the complex-valued Fresnel reflection coefficients for same-sense and crossed polarization $\left(R^{S}, R^{X}\right)$. The loss of coherent power, $S^{2}$, is a polarization-independent function of the wavenumber, $k=2 \pi / \lambda$, and can be written as (Beckmann and Spizzichino, 1963):

$S^{2}=\exp \left(-k^{2} s^{2} \cos ^{2} \theta\right)$

where $\theta$ is the angle of incidence and $\mathrm{s}$ is the standard deviation of surface heights; it accounts for small-scale random height variations with respect to the mean or trend surface (not necessarily planar) (Nievinski and Larson, 2014c).

We can express the interferometric phase $\phi_{i}$ as:

$\phi_{i}=\phi_{X}+k \tau_{i}-\Phi_{d}^{R}$

where $\phi_{X}=\arg (X)$ represents the coupled surface/antenna properties as $X$ above, $\tau_{i}$ is the interferometric propagation delay, and $\Phi_{d}^{R}$ is the direct signal antenna phase contribu- tion. For a horizontal surface, the delay, $\tau_{i}$, can be modeled as a function of the satellite elevation angle (e) and the socalled reflector height, the vertical distance between the GPS antenna phase center and the reflecting surface, $H$, (Georgiadou and Kleusberg, 1988):

$\tau_{i}=2 H \sin e$

Finally, we quantify the visibility of fringes (dSNR) against the background trend (tSNR) as:

$\mathrm{vSNR}_{\mathrm{dB}}=\mathrm{SNR}_{\mathrm{dB}}-\mathrm{tSNR}_{\mathrm{dB}}=(1+\mathrm{dSNR} / \mathrm{tSNR})_{\mathrm{dB}}$

where $\mathrm{tSNR}_{\mathrm{dB}}$ is expressed in decibels and tSNR is not. Clearly, fringe visibility $\mathrm{vSNR}_{\mathrm{dB}}$ is not simply detrended SNR in decibels, $\mathrm{dSNR}_{\mathrm{dB}}$. This is shown in Fig. 2, where the elevation angle axis is expressed uniformly with sine of elevation angle, thus also linearly with interferometric delay (Eq. (7)).

\section{Theoretical performance}

The open source multipath simulator of Nievinski and Larson (2014a) has been extended here by adding support for the L5 GPS carrier frequency and modulation properties. The modified software is made available at https:// www.ngs.noaa.gov/gps-toolbox/MPsimul.htm.

One parameter that needed to be included was the variation in minimum received power for L5 as a function of elevation angle. Unfortunately, in contrast to legacy signals, this parameter is not defined in the GPS interface specification (GPSD-USAF, 2011). However, measurements made by Erker et al. (2010) indicate that L5 behaves similar to L2. In the simulator, the elevation angle dependent variation in power (with respect to its value at $5^{\circ}$ ) for L5 is defined to be equal to that of L2. Now the effect of various frequency/code combinations can be simulated.

\subsection{Synthetic observations}

First the effect of changes in antenna height on the interferometric delay and power are considered. Fig. 3 provides fringe visibility for a geodetic antenna installed upright at heights ranging from 0.5 to $3.0 \mathrm{~m}$. In this setup, the assumption is made that the reflections occur on a horizontal surface with negligible roughness. For increasing antenna height, an increasing number of fringe cycles are observed as the satellite rises at the horizon mask to zenith. Signal power changes are also evident. For that particular 


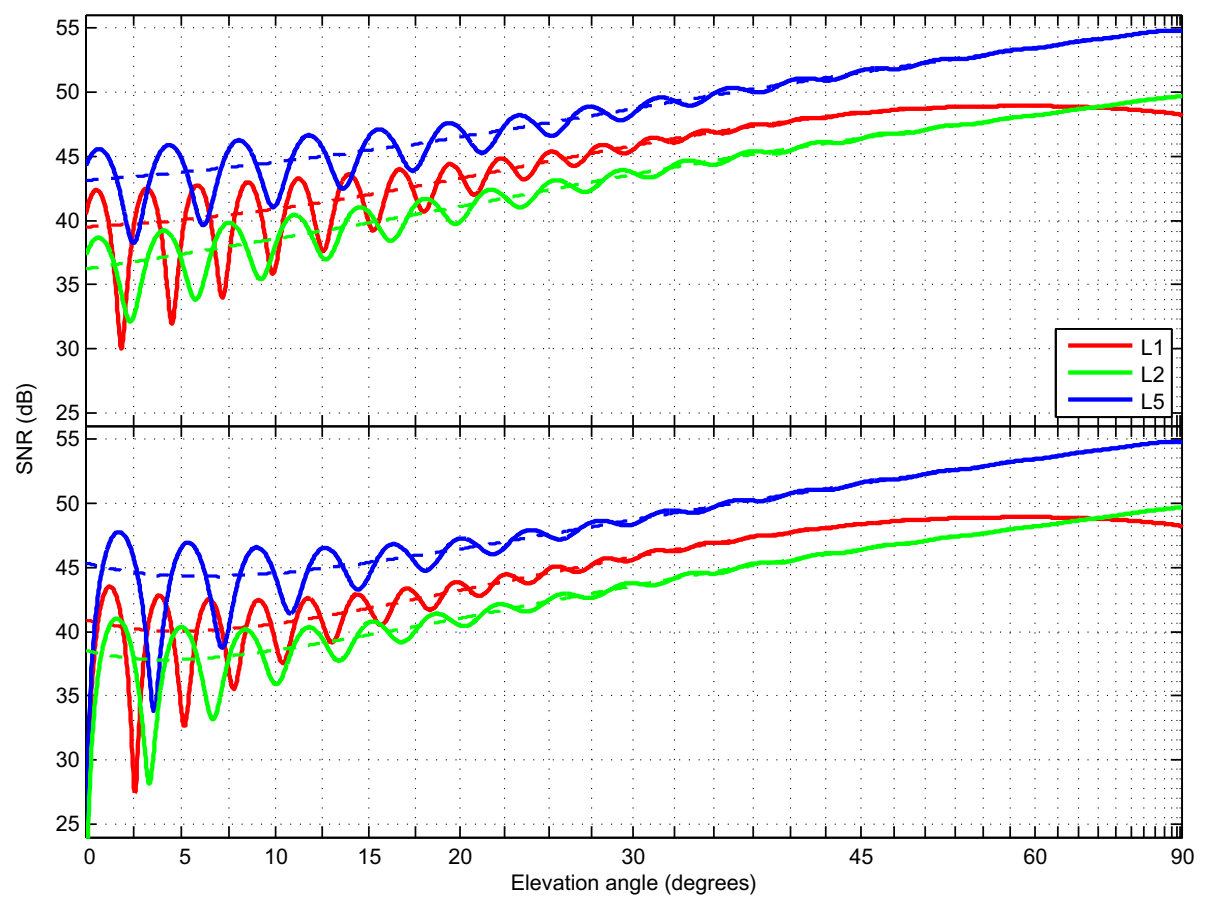

Fig. 2. SNR and its trend (dashed line) for a geodetic antenna (TRM57971.00) installed on $2.0 \mathrm{~m}$ high over a surface with 10-cm random roughness; top, and bottom panels refer to surface material set to PEC and average dry/wet ground, respectively.

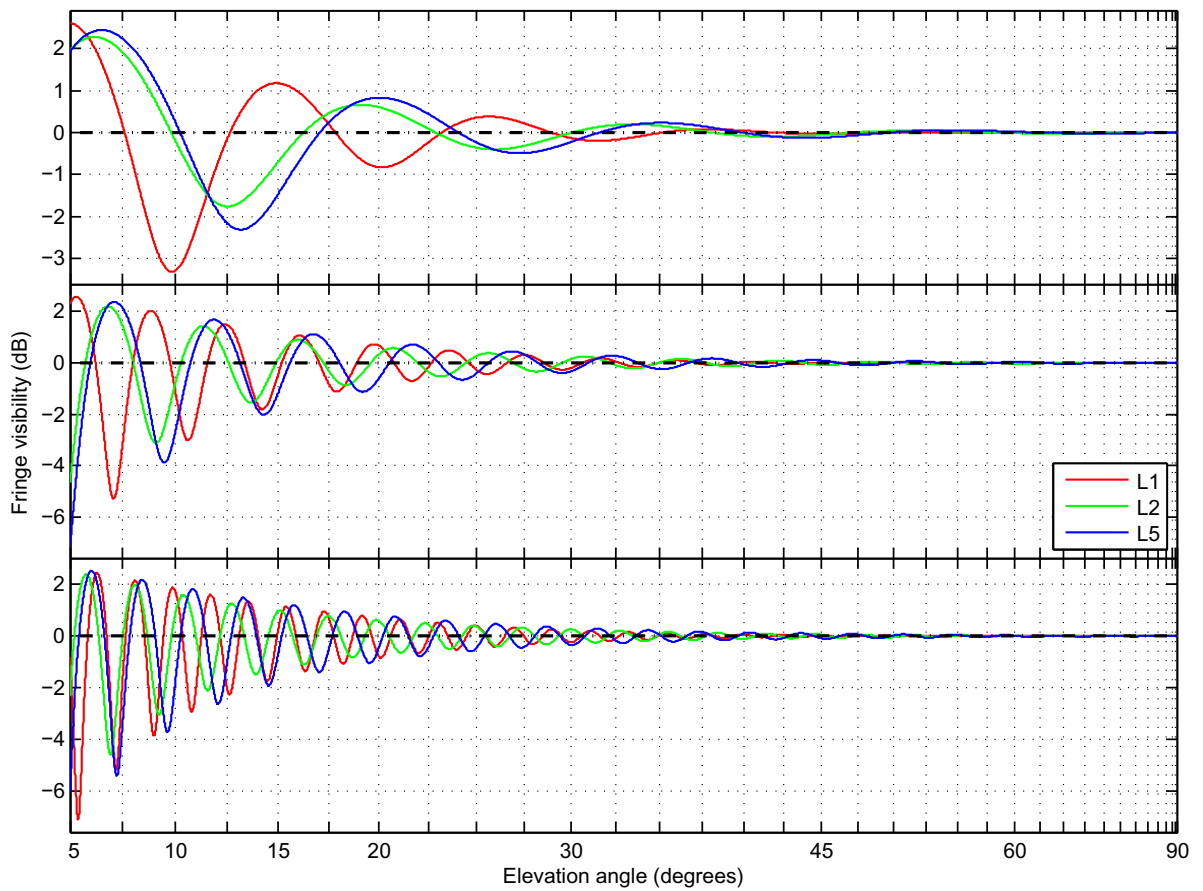

Fig. 3. Impact of reflector height on fringe visibility at GPS L1, L2, and L5 carriers as a function of antenna height for a geodetic antenna (TRM57971.00) and average dry/wet ground surface material; top, middle, and bottom panels refer to $0.5,1.5$, and $3.0 \mathrm{~m}$ reflector height values, respectively.

antenna, L5 is the strongest while L1 and L2 have similar power.

The multipath modulation is a consequence of both geometrical and compositional properties of the surface. Different material properties, e.g. wet ground versus dry ground, also produce different interferometric delay and power (Fig. 4). Overall the L5 signal has larger amplitudes, an observation which seems to provide improved noise performance, especially in less electrically conductive materials. The one exception is for a perfectly electrically conducting 
(PEC) surface, where L1 has greater amplitudes; this feature is even more pronounced for choke-ring antennas, whose quarter-wavelength deep, eighth-wavelength spaced corrugations are tuned for multipath mitigation at L2 band (Young et al., 1988).

One phenomenon that causes loss of coherent power is random surface roughness. Fig. 5 shows the simulated interference fringes for an antenna installed on a 2-m tall monument. Increasing surface roughness decreases multipath modulation power and causes the visibility or range of fringes to decrease. Random surface roughness is beneficial for GPS positioning, as for a given surface reflectivity, decoherence mitigates multipath errors in carrier-phase and pseudorange observables; please see Nievinski and Larson, 2014b for details.

These simulations illustrate the usefulness of multiple carrier frequencies for estimating common physical parameter that produce different effects at each carrier, such as the standard deviation of surface heights, s (carrier-independent) and the resulting carrier-dependent $S^{2}$ factor (Eq. (5)).

\subsection{Parameter retrievals}

Given that stronger reflected signals are desirable in GPS-MR, observations from satellites with elevation angles between $5^{\circ}$ and $30^{\circ}$ are used. Observations from an area with no surface roughness and vegetation are simulated. Combining Eqs. (6) and (7) yields $4 \pi \lambda^{-1} \sin e$, which if it is taken as an independent variable for SNR observations, it produces a spectrum whose frequency domain is expressed in terms of reflector height, $H$ (Larson et al.,
2009). Least-squares spectral analysis (Wells et al., 1985), also known as the Lomb-Scargle periodogram, was applied to estimate the best-fitting sinusoid. Detrended SNR was utilized, as it most resembles a sinusoid, in contrast to fringe visibility, which exhibits narrower destructiveinterference troughs compared to the neighboring constructive-interference peaks. Snow depth can be obtained by subtracting the initial value for snow-free ground height from the snow-covered ground. Finally, the retrieved or output depth value is compared to its known value as input to generate the synthetic SNR observations; their difference can be interpreted as the retrieval error, shown in Fig. 6.

For large reflector heights, the relationship is almost perfectly one-to-one, with an error of a few $\mathrm{cm}$ for meterlevel depth values. More importantly for the present analysis, the estimated snow depth with L2 and L5 signals are very close. However, when the snow surface approaches the height of the antenna, the retrieval deteriorates, as the low-frequency modulation gets mixed up with the low-order polynomial trend. For L2 and L5, this ceiling is hit at a snow depth that is smaller than that for L1. This effect occurs because the $\mathrm{L} 1$ wavelength is $20-25 \%$ smaller, thus more interference fringe cycles are visible between the same observation interval $\left(5-30^{\circ}\right.$ in elevation angle). In previous GPS-MR studies (Larson and Nievinski, 2013), $0.5 \mathrm{~m}$ was reported to be the minimum antenna height at which a reflector height can be successfully retrieved. When more than two complete fringes are contained in the signal, spectral analysis can be used to resolve the frequency. If there are an insufficient number of cycles, the detrending polynomial could inadvertently remove some portion of the modulation. The colinearity of the modulation

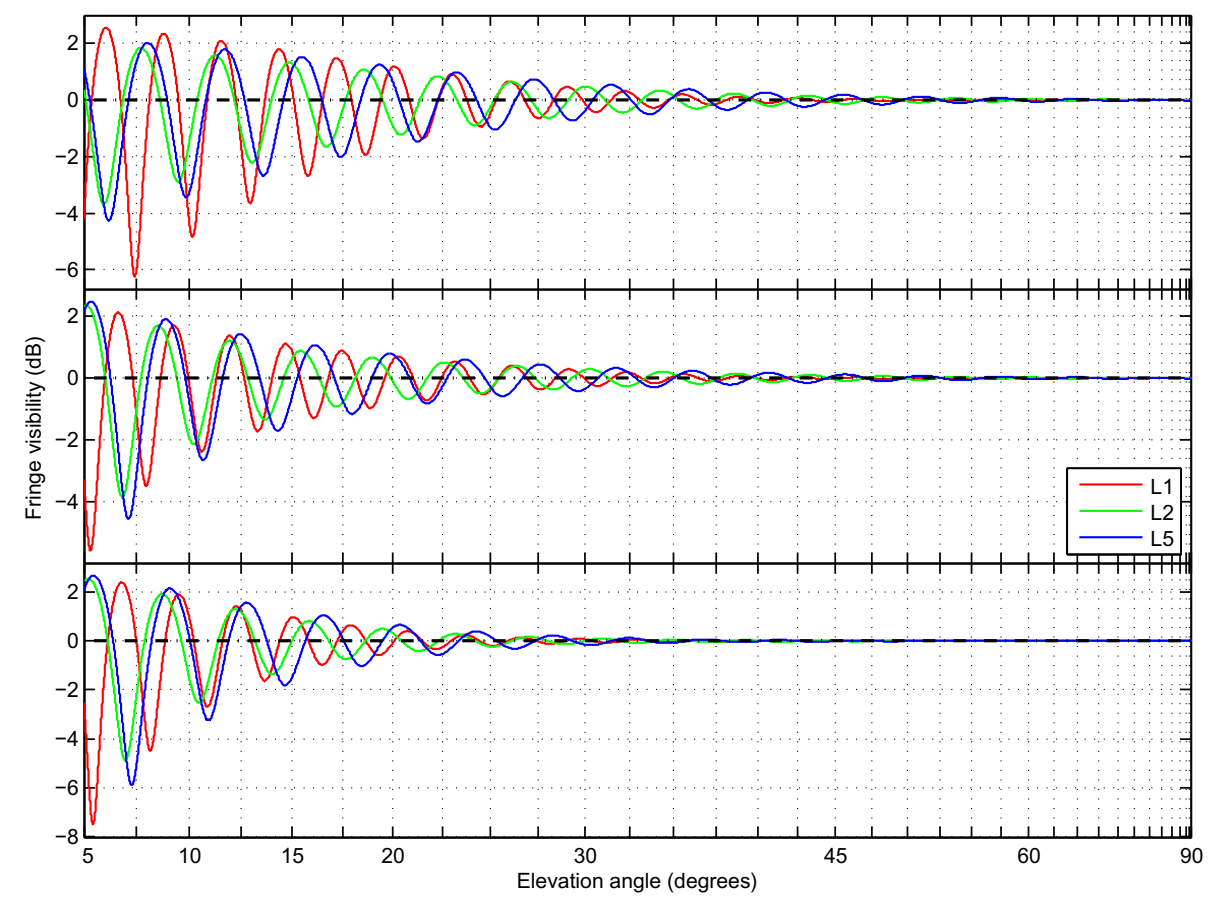

Fig. 4. Impact of different surface materials on fringe visibility at GPS L1, L2, and L5 carriers for a geodetic antenna (TRM57971.00) installed on 2.0 m high over a smooth surface; top, middle, and bottom panels refer to PEC, wet ground, and dry snow, respectively. 


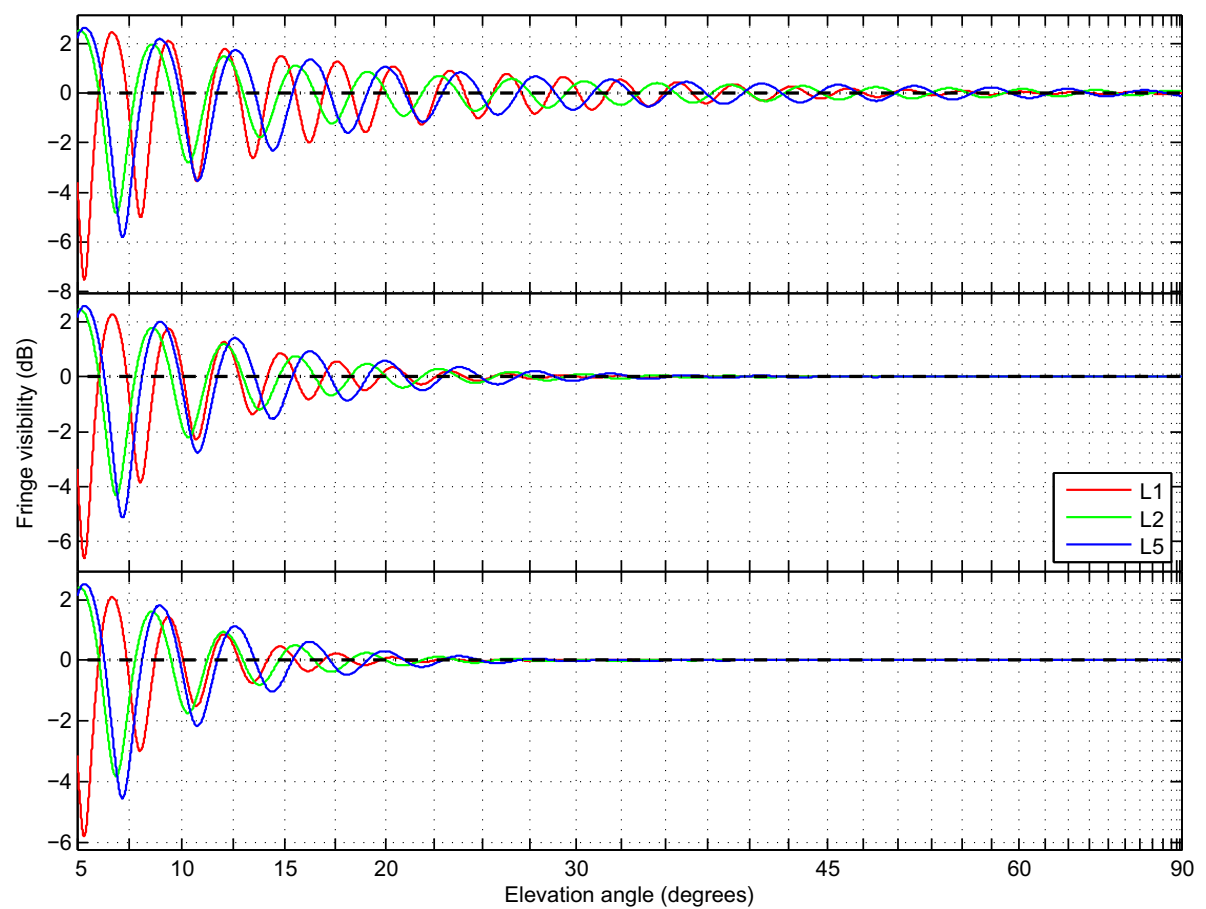

Fig. 5. Effect of different surface roughnesses on fringe visibility at GPS L1, L2, and L5 carriers as for a geodetic antenna (TRM57971.00) installed $2 \mathrm{~m}$ high over average dry/wet ground surface material; top, middle, and bottom panels refer to 5, 15, and $20 \mathrm{~cm}$ surface height standard deviation, respectively.

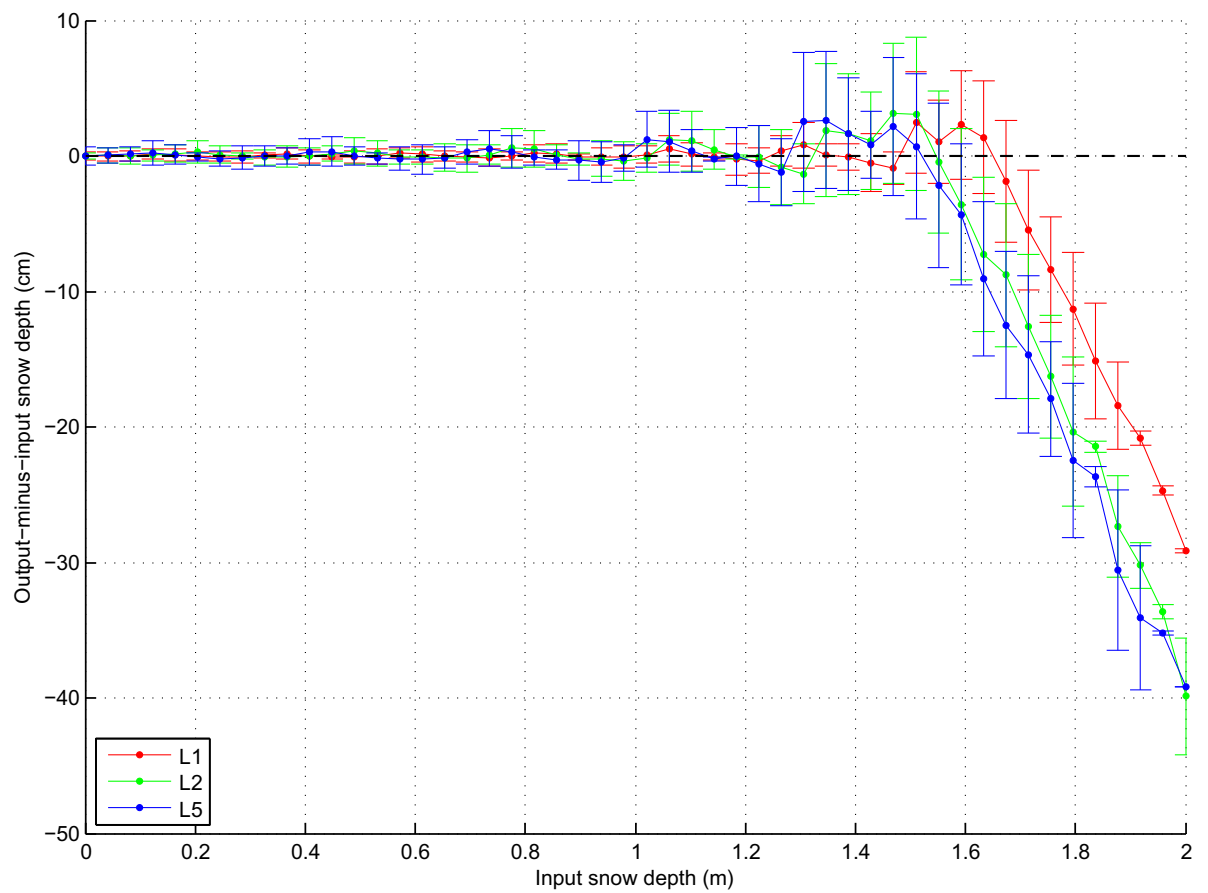

Fig. 6. Bias in best-fitting reflector height for each carrier frequency; antenna height is held fixed at $2 \mathrm{~m}$ and the ground is overlaid with a snow layer of variable thickness; each dot represents an average over four equally spaced phase shifts $\left(0^{\circ}, 45^{\circ}, 90^{\circ}\right.$, and $\left.135^{\circ}\right)$; the errorbar represents the spread among these four estimates.

frequency and phase-shift in their functional relationship is another problem with reflector heights that are too shallow. Hence, the modulation frequency and phase-shift will become correlated and their uncertainty will become inflated.

\section{Experimental performance}

At two locations in Colorado, USA, SNR measurements were collected on the GPS L2 and L5 carriers (Fig. 7). The SNR trend changes from 31 to $48 \mathrm{~dB}-\mathrm{Hz}$ 


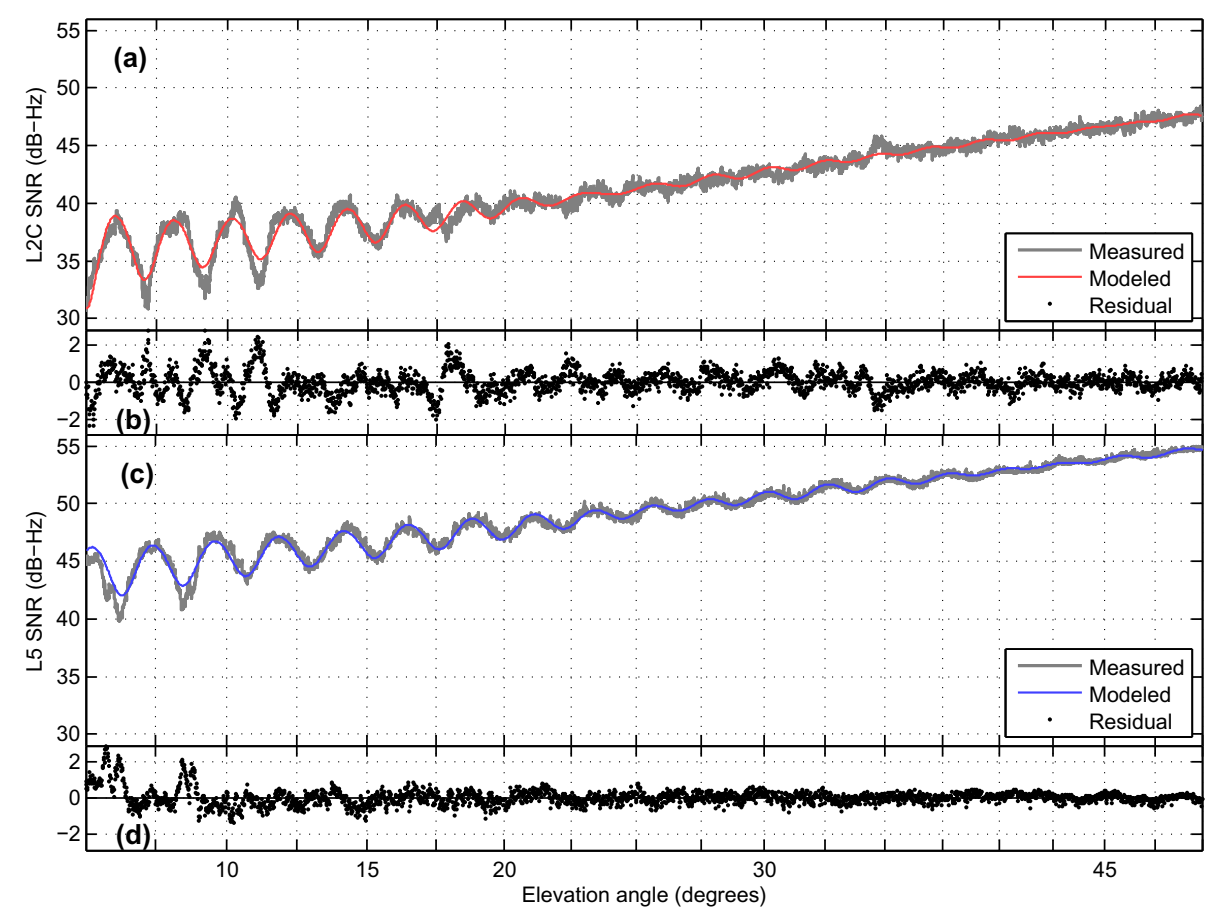

Fig. 7. (a) Observed L2C SNR and best-fitting detrended sinusoid for a rising arc of satellite 25 observed from a geodetic-quality GPS antenna; (b) residual of (a); (c) same as (a) but for L5; (d) residual of (c); the data was recorded by a station located in a wheat field which had been harvested just prior to epoch reported in this figure.

for $\mathrm{L} 2$ and from 40 to $55 \mathrm{~dB}-\mathrm{Hz}$ for L5. The oscillations superimposed on this trend are caused by interference of the direct and reflected GPS signals. A low-order polynomial is used to detrend the data. The amplitude of oscillations is larger in L5 versus L2. As in the simulations discussed in Section 4.2, we fit a sinusoid to detrended SNR, an univariate interferogram, to quantify the multipath modulation frequency, phase shift, and amplitude. The best-fitting sinusoid parameters can be related to environmental variables in the immediate surroundings of the antenna. For snow depth studies, multipath modulation frequency is estimated as an independent unknown. In contrast, for soil moisture studies, frequency is constrained to its median value evaluated over preliminary estimates during the campaign period, after which just amplitude and phase shift are estimated independently (Chew et al., 2014). To make results comparable, we employed only L5- and L2C-broadcasting block-IIF satellites for both L5 and L2 analyses, i.e., we discarded the portion of L2C-broadcasting satellites that did not also broadcast L5.

\subsection{Snow depth}

Data from a GPS station in Niwot Ridge, Colorado, is used to compare the GPS-MR derived snow depth from L2 and L5 carriers. A Trimble NetR8 receiver and a TRM41249.00 antenna (as per IGS designations) with no external radome was used at this station. As this antenna is not advertised as L5-capable, it begs explaining why tracking was possible. Although this antenna shares the same resistive ground-plane as the L5-capable TRM57971.00, this older model (TRM41249.00) was manufactured before the start of L5 broadcasts. Yet its original broad-band design "is inherently suited to application in a three frequency antenna design, as will be required [in the future] for simultaneous reception of L1, L2 and L5 signals" (Krantz et al., 2001). Latter model versions updated the low-noise amplifier (LNA) to encompass more of the L5 bandwidth, but the original LNA band-pass filter did not overly attenuate the L5 band, despite a $\sim 10$-dB penalty (Solarić et al., 2009).

The antenna was installed three meters above the ground to make sure that it would not get buried in the snow. A 86-day period during the summer of 2012 was used to determine the antenna height above the snow-free ground. Fig. 8 shows GPS-MR-derived snow depth from the two carriers. L2 snow retrievals ranged from zero to $1.27 \mathrm{~cm}$ and $\mathrm{L} 5$ ones ranged from zero to $1.23 \mathrm{~cm}$. The RMSE between the two is $2.06 \mathrm{~cm}$, with a very strong correlation, exceeding 0.995 . Their regression intercept, $0.32 \pm 0.24 \mathrm{~cm}$, is barely statistically significant (Fig. 9). The deviation from unity in the regression slope $0.99999 \pm 0.0064 \mathrm{~cm} / \mathrm{cm}$ is also insignificant, indicating the absence of detectable biases in GPS-MR retrievals between L2 and L5.

\subsection{Soil moisture}

GPS station P041 is located in Boulder, Colorado, where the surface is nearly horizontal and vegetation is 


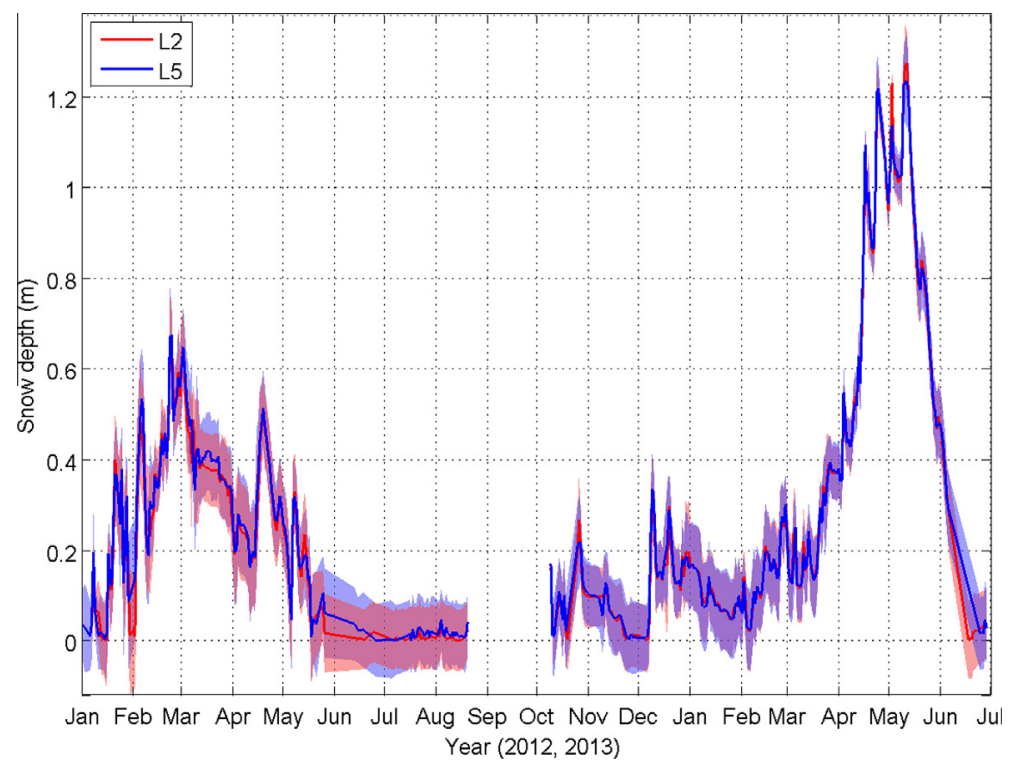

Fig. 8. Comparison of GPS snow depth retrievals based on L2 and L5 carrier frequencies; errorbars estimated from the variation between GPS satellite tracks at different azimuths, for each carrier frequency separately.

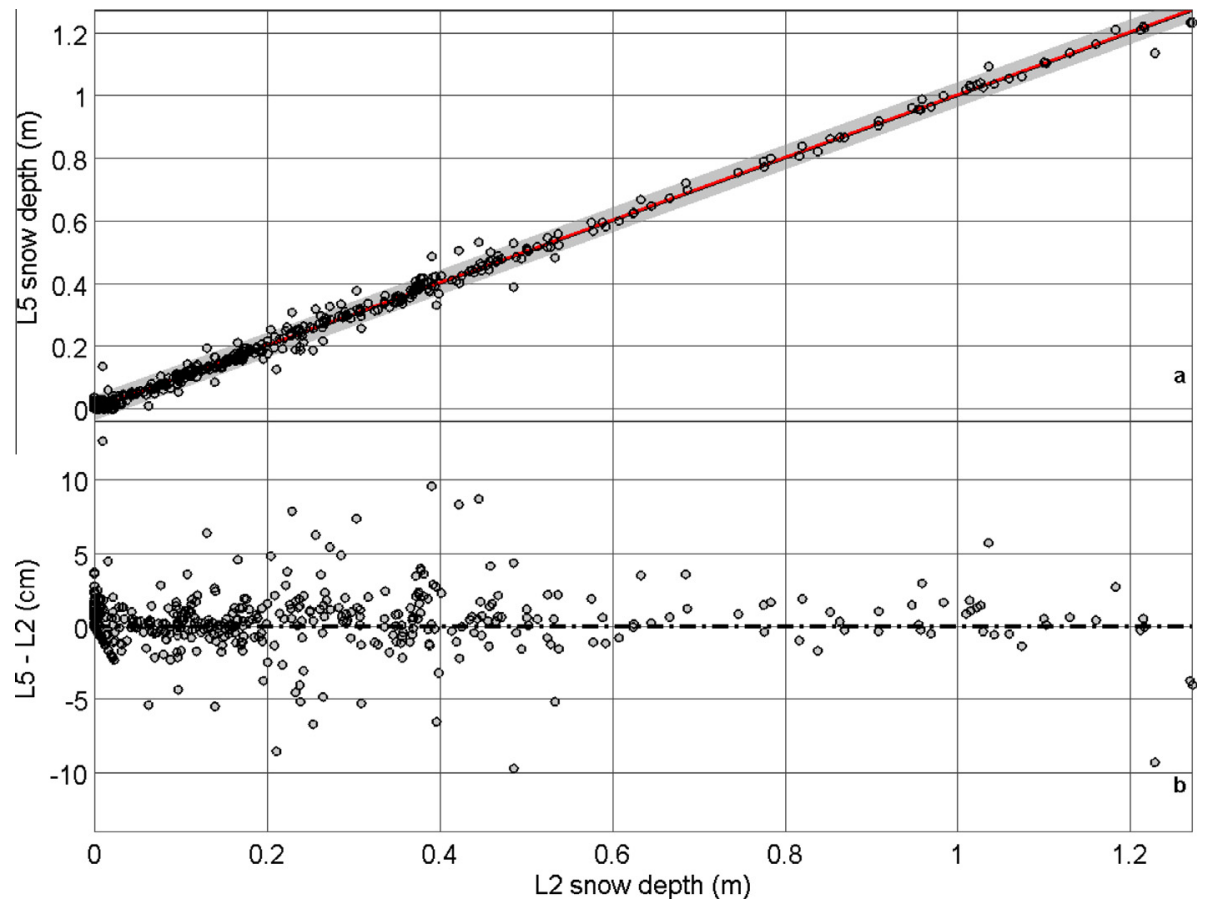

Fig. 9. (a) Relationship between L2-derived snow depth and L5-derived snow depth; a linear regression is shown in red where $95 \%$ prediction intervals is shown as a light-gray band. (b) Post-fit residuals.

sparse. Data from this site was used to compare the GPSMR derived soil moisture from L2 and L5 carrier frequencies. An L5-capable Trimble NetR9 receiver was installed on February 20, 2013. Antenna TRM29659.00 with SCIT radome is installed $\sim 2.0 \mathrm{~m}$ above the ground in this station. Although this model shares the same choke-ring as the L5-capable TRM59800.00 and TRM59900.00, it was not designed specifically for L5. This situation is similar to that between models TRM41249.00/TRM57971.00 at the NWOT site, except that in the present case the ground-plane is made of metallic choke-rings instead of a resistive material. Again tracking is possible (Bartone, 2006) and indeed we found it attainable, notwithstanding a few-dB penalty.

Observations between elevation angles of $5-30^{\circ}$ we used, as they are the most sensitive to multipath. A metric phase shift instead of angular phase shift is reported because it yields a more direct relationship between the two carriers. 


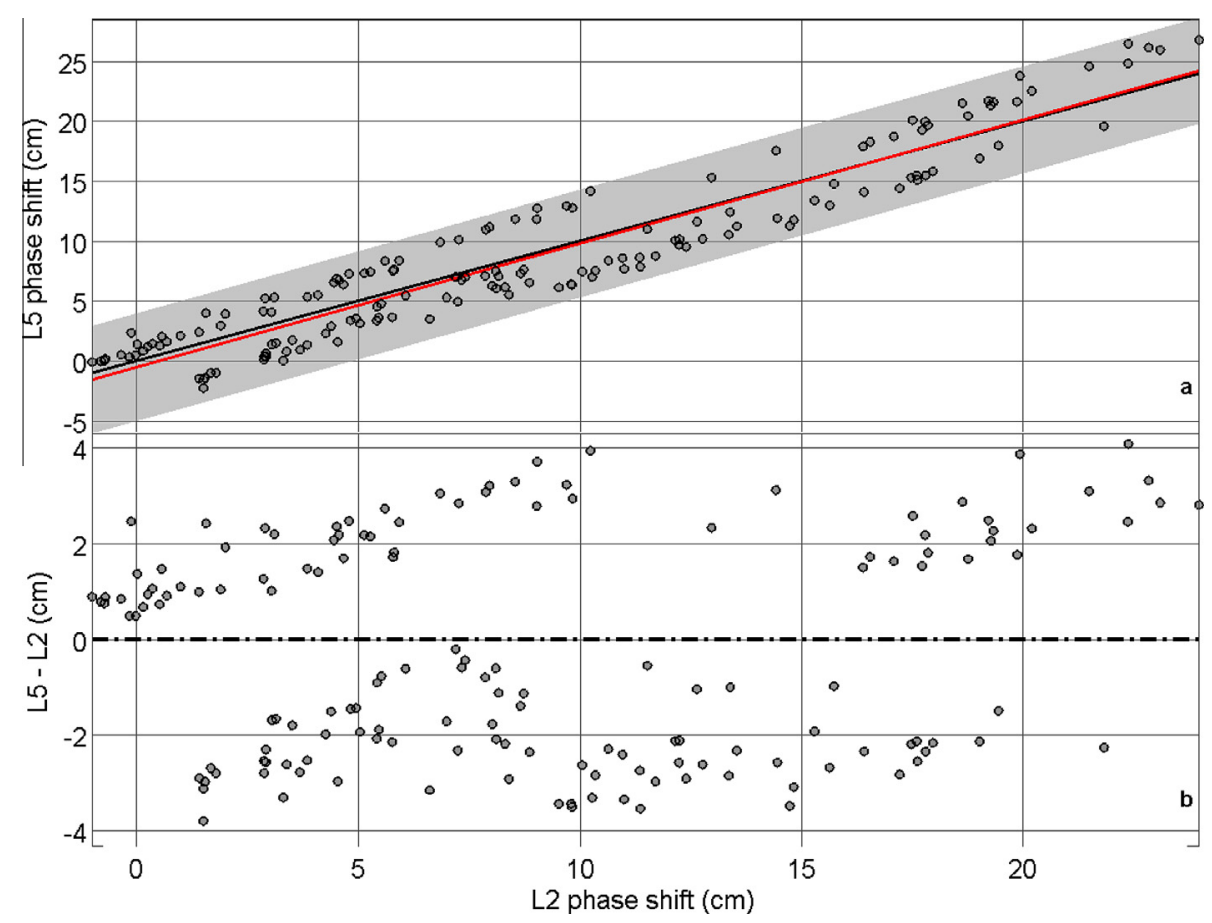

Fig. 10. (a) Relationship between L2- and L5-derived phase shift; a linear regression is shown in red where 95\% prediction intervals is shown as a lightgray band. (b) Post-fit residuals.

Estimated phase shifts were zeroed using the 5th percentile at each carrier. Fig. 10 shows results for a five-month period (May 3rd to October 2nd, 2013) for L2 and L5. Over this period, multipath was driven by the soil/vegetation medium; days affected by snow have been excluded. Carrying out a regression between retrievals from the two carriers, the intercept $-0.53 \mathrm{~cm} \pm 0.61 \mathrm{~cm}$ is not statistically significant vis-à-vis its $95 \%$ confidence interval, whereas the regression slope, $1.032 \mathrm{~cm} / \mathrm{cm} \pm 0.056 \mathrm{~cm} / \mathrm{cm}$, does not deviate significantly from a one-to-one relationship.
This indicates again the lack of detectable biases in L2/ L5 GPS-MR for snow depth sensing; a result which was a source of concern up to now, because of different carrier wavelengths that causes slightly different moisture sensing depths and horizontal footprint coverage.

Estimated phase shifts with in-situ volumetric soil moisture content (VSMC) were compared; the probe was installed $2.5 \mathrm{~cm}$ deep and read every $30 \mathrm{~min}$. The regression intercept of L2 phase shifts and VSMC is $0.0401 \mathrm{~cm}^{3} /$ $\mathrm{cm}^{3} \pm 0.0113 \mathrm{~cm}^{3} / \mathrm{cm}^{3}$ and the regression slope is 0.0096

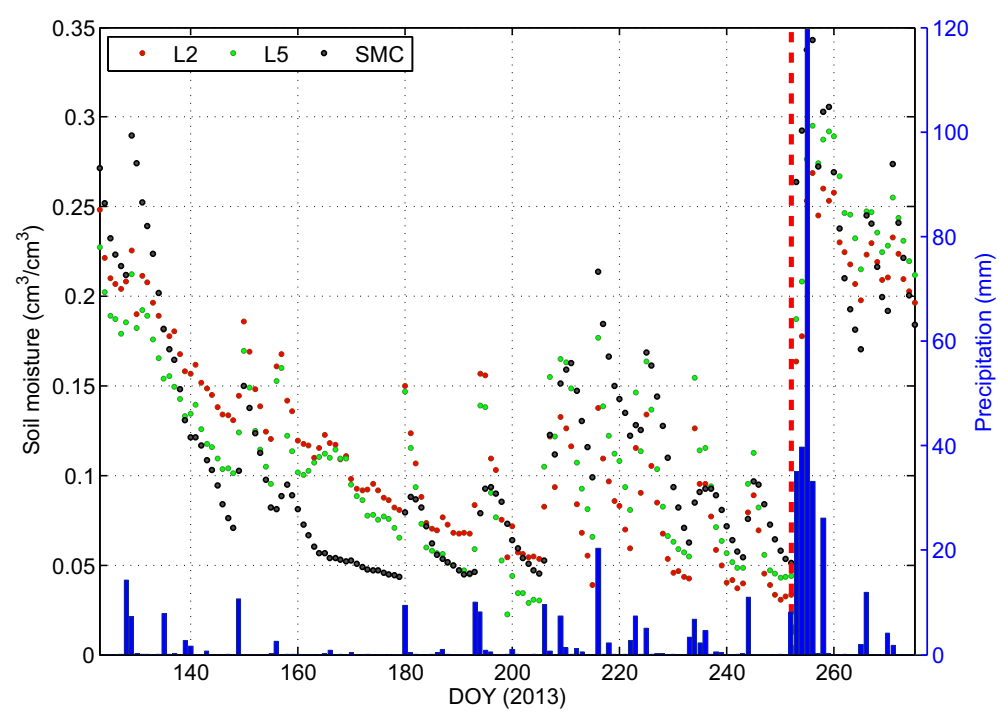

Fig. 11. Comparison of GPS-derived soil moisture using L2 and L5 carrier frequencies and volumetric soil moisture averaged over the top $5 \mathrm{~cm}$ and daily precipitation (in-situ temperatures were above $0{ }^{\circ} \mathrm{C}$ ). 
$\left(\mathrm{cm}^{3} / \mathrm{cm}^{3}\right) \cdot \mathrm{cm}^{-1} \pm 0.001\left(\mathrm{~cm}^{3} / \mathrm{cm}^{3}\right) \cdot \mathrm{cm}^{-1}$. For comparison, regression between L5 phase shift and VSMC indicated an intercept of $0.0437 \mathrm{~cm}^{3} / \mathrm{cm}^{3} \pm 0.0086 \mathrm{~cm}^{3} / \mathrm{cm}^{3}$ and slope of $0.0094\left(\mathrm{~cm}^{3} / \mathrm{cm}^{3}\right) \cdot \mathrm{cm}^{-1} \pm 0.0008\left(\mathrm{~cm}^{3} / \mathrm{cm}^{3}\right)$ $\cdot \mathrm{cm}^{-1}$. Again, the differences of regression coefficients are not statistically significant; the uncertainties indicate that L2-derived phase shifts are noisier than that of L5.

Fig. 11 shows a scatter plot of the GPS-derived vs. insitu VSMC. The red dashed-line indicates the onset of the catastrophic 2013 Colorado flooding event. The correlations between both L2 and L5 and in-situ data are good, with $r^{2}$ values of values of 0.693 and 0.797 , respectively. In hindsight, these large correlations benefit from the wide range of VSMC observed, a sevenfold variation. In contrast, if only the driest or only the wettest conditions were observed, the linear relationship underlying the correlation measure would not have been established so well. Again, the L5 RMS error is slightly smaller than that of L2: $0.034 \mathrm{~cm}^{3} / \mathrm{cm}^{3}$ vs. $0.042 \mathrm{~cm}^{3} / \mathrm{cm}^{3}$, respectively.

\section{Conclusions}

Results have demonstrated that modernized GPS signal-to-noise ratio (SNR) can be used reliably for GPS multipath reflectometry (GPS-MR). Using the newest modernized L5 GPS signal, the forward and inverse modeling of SNR observations for GPS-MR have been investigated. The L5 signal, due to its availability on different global satellite navigation systems, will become more and more important in the future. The effects of three GPS carrier frequencies on various medium permittivities were tested. The results indicate that the L5 signal is as sensitive to surface/antenna geometry as is L2C. In addition, L5 (its Q sub-code) has the strongest effective power, which allied with its shorter code length contributes to clearer fringe visibility and better tracking noise performance. Multiple carrier frequencies respond differently to some of the same physical parameters (Figs. 3-5), which raise the prospects for combining dual- and triple-frequency SNR to isolate these carrier-independent parameters. Because of its larger wavelength, L5 was slightly worse in estimating the low range of reflector heights than L2, with L1 being significantly better than both L2 and L5 (Fig. 6) when the reflecting surface is not at least $50 \mathrm{~cm}$ higher than the antenna (otherwise, all carriers perform equally well). Snow depth and soil moisture based on L5 are statistically equivalent to $\mathrm{L} 2 \mathrm{C}$-derived retrievals, demonstrating the lack of detectable biases in L2/L5 GPS-MR, which was suspected as a consequence of their wavelength difference. On the other hand, soil moisture retrieval errors, as compared to in-situ data, indicate that L2-derived retrievals are slightly noisier than those of L5.

\section{Acknowledgments}

ST is funded by the Fonds National de la Recherche, Luxembourg, reference no. 1351102. FGN acknowledges
CNPq - Brazil award no. 372541/2013-5. Some of this material is based on data, equipment, and engineering services provided by the Plate Boundary Observatory operated by UNAVCO for EarthScope (http://www. earthscope.org) and supported by the National Science Foundation - United States (EAR-0350028 and EAR-0732947). The authors would like to thank Prof. K.M. Larson and Prof. E.E. Small providing VSMC data in Boulder, Colorado (NSF AGS 0740515 and NASA - United States NNH10ZDA001 N). Reviewers are thanked for their extensive comments and suggestions.

\section{References}

Alonso-Arroyo, A., Camps, A., Aguasca, A., Forte, G.F., Monerris, A., Rudiger, C., Walker, J.P., Park, H., Pascual, D., Onrubia, R., 2014. Dual-polarization GNSS-R interference pattern technique for soil moisture mapping. IEEE J. Sel. Top. Appl. Earth Obs. Remote Sens. 7, 1533-1544. http://dx.doi.org/10.1109/JSTARS.2014.2320792.

Anderson, K.D., 2000. Determination of water level and tides using interferometric observations of GPS signals. J. Atmos. Oceanic Technol. 17, 1118-1127. http://dx.doi.org/10.1175/1520-0426(2000) 017<1118:DOWLAT>2.0.CO;2.

Bartone, C., 2006. GNSS solutions: will I need a new antenna for the new GPS and Galileo signals? Will one antenna work for both systems? InsideGNSS, 21-22.

Beckmann, P., Spizzichino, A., 1963. The Scattering of Electromagnetic Waves from Rough Surfaces. Pergamon Press.

Chew, C.C., Small, E.E., Larson, K.M., Zavorotny, V.U., 2014. Effects of near-surface soil moisture on GPS SNR data: development of a retrieval algorithm for soil moisture. IEEE Trans. Geosci. Remote Sens. 52, 537-543. http://dx.doi.org/10.1109/TGRS.2013.2242332.

Dobson, M.C., Ulaby, F.T., Hallikainen, M.T., El-Rayes, M., 1985. Microwave dielectric behavior of wet soil - Part II: dielectric mixing models. IEEE Trans. Geosci. Remote Sens. GE-23, 35-46. http:// dx.doi.org/10.1109/TGRS.1985.289498.

Elósegui, P., Davis, J.L., Jaldehag, R.T.K., Johansson, J.M., Niell, A.E., Shapiro, I.I., 1995. Geodesy using the global positioning system: the effects of signal scattering on estimates of site position. J. Geophys. Res. 100, 9921-9934. http://dx.doi.org/10.1029/95JB00868.

Erker, S., Thoelert, S., Meurer, M., 2010. On the air new signals from the first GPS IIF satellite. InsideGNSS, 28-35.

Fontana, R.D., Cheung, W., Novak, P.M., Stansell, T.A., 2001. The new L2 civil signal, in: ION GPS. In: Presented at the Proceedings of the 14th International Technical Meeting of the Satellite Division of The Institute of Navigation (ION GPS 2001), The Institute of Navigation, Salt Lake City, UT, pp. 617-631.

Georgiadou, Y., Kleusberg, A., 1988. On carrier signal multipath effects in relative GPS positioning. Manuscripta Geod. 13, 172-179.

Gleason, S., Lowe, S., Zavorotny, V., 2009. Remote sensing using bistatic GNSS reflections. In: Gleason, S., Gebre-Egziabher, D. (Eds.), GNSS Applications and Methods. Artech House, pp. 399-436.

GPSD-USAF, 2011. Navstar GPS Space Segment/Navigation User Segment Interfaces. Revision F (IS-GPS-200F).

GPSD-USAF, 2012. Navstar GPS Space Segment/Navigation User Segment Interfaces. Revision F (IS-GPS-705C).

Hallikainen, M.T., Ulaby, F.T., Dobson, M.C., El-Rayes, M., Wu, L.-K., 1985. Microwave dielectric behavior of wet soil - Part 1: empirical models and experimental observations. IEEE Trans. Geosci. Remote Sens. GE-23, 25-34. http://dx.doi.org/10.1109/TGRS.1985.289497.

Jacobson, M.D., 2008. Dielectric-covered ground reflectors in GPS multipath reception - theory and measurement. IEEE Geosci. Remote Sens. Lett. 5, 396-399. http://dx.doi.org/10.1109/LGRS.2008.917130.

Jin, S.G., Cardellach, E., Xie, F., 2014. GNSS Remote Sensing: Theory, Methods and Applications. Springer, Netherlands. 
Jin, S., Najibi, N., 2014. Sensing snow height and surface temperature variations in Greenland from GPS reflected signals. Adv. Space Res. 53, 1623-1633. http://dx.doi.org/10.1016/j.asr.2014.03.005.

Kavak, A., Vogel, W.J., Xu, G., 1998. Using GPS to measure ground complex permittivity. Electron. Lett. 34, 254-255. http://dx.doi.org/ 10.1049/el:19980180.

King, M.A., Watson, C.S., 2010. Long GPS coordinate time series: multipath and geometry effects. J. Geophys. Res. 115, B04403. http:// dx.doi.org/10.1029/2009JB006543.

Krantz, E., Riley, S., Large, P., 2001. The design and performance of the Zephyr geodetic antenna. In: ION GPS. Presented at the Proceedings of the 14th International Technical Meeting of the Satellite Division of The Institute of Navigation (ION GPS 2001), The Institute of Navigation, Salt Lake City, UT, pp. 1942-1951.

Larson, K.M., Small, E.E., Gutmann, E.D., Bilich, A.L., Braun, J.J., Zavorotny, V.U., 2008. Use of GPS receivers as a soil moisture network for water cycle studies. Geophys. Res. Lett. 35. http:// dx.doi.org/10.1029/2008GL036013.

Larson, K.M., Gutmann, E.D., Zavorotny, V.U., Braun, J.J., Williams, M.W., Nievinski, F.G., 2009. Can we measure snow depth with GPS receivers? Geophys. Res. Lett. 36, L17502. http://dx.doi.org/10.1029/ 2009GL039430.

Larson, K.M., Braun, J.J., Small, E.E., Zavorotny, V.U., Gutmann, E.D., Bilich, A.L., 2010. GPS multipath and its relation to near-surface soil moisture content. IEEE J. Sel. Top. Appl. Earth Obs. Remote Sens. 3, 91-99. http://dx.doi.org/10.1109/JSTARS.2009.2033612.

Larson, K.M., Ray, R.D., Nievinski, F.G., Freymueller, J.T., 2013. The accidental tide gauge: a GPS reflection case study from Kachemak Bay, Alaska. IEEE Geosci. Remote Sens. Lett. 10, 1200-1204. http:// dx.doi.org/10.1109/LGRS.2012.2236075.

Larson, K.M., Nievinski, F.G., 2013. GPS snow sensing: results from the EarthScope plate boundary observatory. GPS Solution 17, 41-52. http://dx.doi.org/10.1007/s10291-012-0259-7.

Larson, K.M., Small, E.E., 2014. Normalized microwave reflection index: a vegetation measurement derived from GPS networks. IEEE JSTARS 7, 1501-1511. http://dx.doi.org/10.1109/JSTARS.2014.2300116.

Löfgren, J.S., Haas, R., Scherneck, H.-G., 2014. Sea level time series and ocean tide analysis from multipath signals at five GPS sites in different parts of the world. J. Geodyn., SI: Understand the Earth 80, 66-80. http://dx.doi.org/10.1016/j.jog.2014.02.012.

Misra, P., Enge, P., 2011. Global Positioning System: Signals, Measurements, and Performance. Ganga-Jamuna Press, Lincoln, Mass.

Najibi, N., Jin, S., 2013. Physical reflectivity and polarization characteristics for snow and ice-covered surfaces interacting with GPS signals. Remote Sens. 5, 4006-4030. http://dx.doi.org/10.3390/rs5084006.

Nievinski, F.G., Larson, K.M., 2014a. An open source GPS multipath simulator in Matlab/Octave. GPS Solution 18, 473-481. http:// dx.doi.org/10.1007/s10291-014-0370-z.

Nievinski, F.G., Larson, K.M., 2014b. Forward modeling of GPS multipath for near-surface reflectometry and positioning applications. GPS Solution 18, 309-322. http://dx.doi.org/10.1007/s10291-0130331-y.
Nievinski, F.G., Larson, K.M., 2014c. Inverse modeling of GPS multipath for snow depth estimation, Part I: formulation and simulations. IEEE Trans. Geosci. Remote Sens. 52, 6555-6563. http://dx.doi.org/ 10.1109/TGRS.2013.2297681.

Nievinski, F.G., Larson, K.M., 2014d. Inverse modeling of GPS multipath for snow depth estimation, Part II: application and validation. IEEE Trans. Geosci. Remote Sens. 52, 6564-6573. http://dx.doi.org/ 10.1109/TGRS.2013.2297688.

Ozeki, M., Heki, K., 2012. GPS snow depth meter with geometry-free linear combinations of carrier phases. J. Geod. 86, 209-219. http:// dx.doi.org/10.1007/s00190-011-0511-x.

Rius, A., Nogués-Correig, O., Ribó, S., Cardellach, E., Oliveras, S., Valencia, E., Park, H., Tarongí, J.M., Camps, A., van der Marel, H., van Bree, R., Altena, B., Martín-Neira, M., 2012. Altimetry with GNSS-R interferometry: first proof of concept experiment. GPS Solution 16, 231-241. http://dx.doi.org/10.1007/s10291-011-0225-9.

Rodriguez-Alvarez, N., Camps, A., Vall-llossera, M., Bosch-Lluis, X., Monerris, A., Ramos-Perez, I., Valencia, E., Marchan-Hernandez, J.F., Martinez-Fernandez, J., Baroncini-Turricchia, G., Pérez-Gutiérrez, C., Sanchez, N., 2011. Land geophysical parameters retrieval using the interference pattern GNSS-R technique. IEEE Trans. Geosci. Remote Sens. 49, 71-84. http://dx.doi.org/10.1109/ TGRS.2010.2049023.

Rodriguez-Alvarez, N., Aguasca, A., Valencia, E., Bosch-Lluis, X., Camps, A., Ramos-Perez, I., Park, H., Vall-llossera, M., 2012. Snow thickness monitoring using GNSS measurements. IEEE Geosci. Remote Sens. Lett. 9, 1109-1113. http://dx.doi.org/10.1109/ LGRS.2012.2190379.

Small, E.E., Larson, K.M., Braun, J.J., 2010. Sensing vegetation growth with reflected GPS signals. Geophys. Res. Lett. 37, L12401. http:// dx.doi.org/10.1029/2010GL042951.

Solarić, N., Solarić, M., Zrinjski, M., 2009. GPS-antenna Zephyr geodetic. Geodetski list 63, 329-352.

Spilker, J.J., Van Dierendonck, A.J., 2001. Proposed new L5 civil GPS codes. Navigation 48, 135-143.

Wan, W., Larson, K.M., Small, E.E., Chew, C.C., Braun, J.J., 2014. Using geodetic GPS receivers to measure vegetation water content. GPS Solution 1-12. http://dx.doi.org/10.1007/s10291-014-0383-7.

Wells, D.E., Vaníček, P., Demitris, P.Spiros., 1985. Least squares spectral analysis revisited. Department of Surveying Engineering, University of New Brunswick.

Young, L.E., Spitzmesser, D.J., Meehan, T.K., Tranquilla, J.M., 1988. GPS antenna selection: Range and field test results. In: ANTEM '88 Symposium on Antenna Technology and Applied Electromagnetics. Presented at the ANTEM '88 Symposium on Antenna Technology and Applied Electromagnetics, Winnipeg, Manitoba.

Zavorotny, V.U., Larson, K.M., Braun, J.J., Small, E.E., Gutmann, E.D., Bilich, A., 2010. A physical model for GPS multipath caused by land reflections: toward bare soil moisture retrievals. IEEE J. Sel. Top. Appl. Earth Obs. Remote Sens. 3, 100-110. http://dx.doi.org/10.1109/ JSTARS.2009.2033608. 